\title{
Lean thinking to improve emergency department throughput at AORN Cardarelli hospital
}

\author{
Giovanni Improta ${ }^{1 *}$ (D), Maria Romano ${ }^{2,6}$, Maria Vincenza Di Cicco', Anna Ferraro', Anna Borrelli ${ }^{3}$, Ciro Verdoliva ${ }^{4}$, \\ Maria Triassi ${ }^{1}$ and Mario Cesarelli, ${ }^{5,6}$
}

\begin{abstract}
Background: Throughout the world, emergency departments (ED) are characterized by overcrowding and excessive waiting times. Furthermore, the related delays significantly increase patient mortality and make inefficient use of resources to the detriment of the satisfaction of employees and patients. In this work, lean thinking is applied to the ED of Cardarelli Hospital of Naples with the aim of increasing patient flow, improving the processes that contribute to facilitating the flow of patients through the various stages of medical treatment and eliminating all bottlenecks (queue) as well as all activities that generate waste.
\end{abstract}

Methods: This project was performed at National Hospital A.O.R.N. A. Cardarelli of Naples. The historical times of access to the ED were analysed from January 2015 to June 2015, for a total of 16,563 records. Subsequently, starting in November 2015, corrective actions were implemented according to the Lean Approach. Data collected after the introduced improvements were collected from April 2016 to June 2016 and compared to those collected during the starting period.

Results: The results acquired before application of the Lean Thinking strategy illustrated the as-is process with its drawbacks. An analysis of the non-added value activities was performed to identify the procedures that need to be improved. After implementation of the corrective actions, we observed a positive increase in the performance of the ED, quantified as percentages of hospitalized patients according to triage codes and waiting times.

Conclusion: This work demonstrates the applicability of Lean Thinking to ED processes and its effectiveness in terms of increasing the efficiency of services and reducing waste (waiting times).

Keywords: Lean thinking, Emergency department, Public health, Quality improvement

\section{Background}

Recently, the National Health Service (NHS) sustainability challenge has been at the heart of political and technical debate. The challenge asks healthcare companies to seek management solutions to support technical and administrative processes with the aim of improving efficiency, productivity, and the appropriateness and quality of performance. Given this necessity, logical and managerial tools are applied to the management of healthcare companies, including private and public hospitals.

\footnotetext{
* Correspondence: ing.improta@gmail.com

${ }^{1}$ Department of Public Health, School of Medicine and Surgery, University of Naples 'Federico II', Naples, Italy

Full list of author information is available at the end of the article
}

Today, the Lean Management Model is one of the most used models in industrial areas and rapidly spreading throughout the healthcare industry in the United States and Great Britain [1]. Lean Management originates from the Toyota Production System (TPS) [2] and aims to improve efficiency by eliminating particular types of waste (called muda, in Japanese) and activities, which absorb time and resources without adding any value to the production process [3].

The Lean Method exploits a set of tools to streamline processes and to eliminate unnecessary time-consuming steps. Lean thinking [4] seeks to enhance performance and meet customer needs by reducing complexity, improving process flow and removing unnecessary or 
non-value-added activities [5, 6], as has been well described by references [6-8].

The essential aspects of Lean systems are as follows: specified tasks, streamlined communication, simple process architecture, and hypothesis-driven problem solving $[8,9]$.

Since the 1970s, in healthcare competitions, factors such as zero defects, process time reduction, price and relevant customisation have gained great importance $[10,11]$.

To implement the Lean methodology, a healthcare organisation typically has to follow a theoretical path whose main stages are as follows [10]:

- Training Lean specialists and raising awareness about waste inside the processes.

- Determining the sequence of activities within the processes using tools such as Value Stream Map (VSM).

- Eliminating activities that do not add value to the process and designing the future state of the process.

- Improving the process (start over) through reactive teams that remove waste when it is identified.

- Using standardised Lean tools.

Lean principles have been successfully adapted to the healthcare environment, enabling hospitals and clinics to streamline their operations and to focus on value as perceived by their patients. Many healthcare organizations have sought the support of Lean manufacturing to improve their efficiency $[12,13]$.

Literature about Lean theory applied to healthcare is relatively recent. However, there are many scientific papers that deal with the subject [11] and demonstrate the benefits of applying Lean methodology in health systems $[1,14]$. In particular, literature reviews indicate that Lean process tools have been successfully applied in the healthcare environment to a wide range of clinical situations, such as the choice of a prosthetic substitute, risk management and reduction of length of hospital stay $[12,15,16]$.

Van Lent et at. [15] applied a Lean thinking approach for a hospital-based chemotherapy day unit. The method improved the process design and led to increased efficiency and more timely delivery of care. Bisgaard et al. [16] investigated the reduction of the length of stay of patients with chronic obstructive pulmonary disease. Their results illustrate the possibilities of improving quality while simultaneously reducing costs.

Other studies focused on improving the performance of the provided services $[17,18]$, developing and using quality indicators [19], reducing medical errors [20] and improving quality and efficiency of healthcare processes using both Lean, Six Sigma and further management or mathematical tools [21-30].
Lean tools have significant applicability in the Emergency Department (ED); throughout the world, EDs are challenged with problems of overcrowding and excessive waiting time [31-35].

Overcrowding and related delays increase patient mortality, decrease the satisfaction of employees and patient sand make inefficient the use of resources [1]. In addition, the ED is considered the heart of a hospital; thus, it critically impacts the organization.

Dickson et al. [17] used Lean manufacturing techniques in the ED in an effort to enhance patient and staff satisfaction. The implementation followed a six-step process of Lean education, ED observation, patient flow analysis, process redesign, and new process testing. Their results demonstrated a slight decrease in length of stay and a significant increase in patient satisfaction without raising the cost per patient. Furthermore, a recent review by Holden [31] on Lean applications indicates that Lean can help to decrease waiting times, length of stay, and the proportion of patients who leave the emergency room before a doctor has examined them.

The key elements for the success of Lean methodology in an ED is the ability to change, the involvement of the leadership, a clear mapping of processes and the introduction of small improvements that are long-term sustainable $[17,35,36]$. Such initiatives need to be realistic and improve patient satisfaction without overloading the work of staff.

The project here was performed at Hospital National Company "AORN Cardarelli" of Naples. Our project primarily aimed to improve the management of patients in the ED, in particular focusing on the following:

- Increase the flow to the client/patient, where the value is effectively measured by the time spent by the patient prior to receiving care within the ED;

- Improve the processes that contribute to the value of the clinical services and to facilitate transitions (flow) of patients through the various stages of medical treatment;

- Eliminate all bottlenecks, as well as all activities that generate waste and create queues

\section{Methods}

The authors, in collaboration with a team of doctors and nurses, conducted a Lean Methodology assessment and thus conducted a study on lead times of all patients who had access to the Emergency Department of AORN Cardarelli before and after the application of Lean. The AORN A. Cardarelli is a hospital of national relief; it represents the largest hospital within South Italy and increasingly within the entire Italian peninsula. Indeed, its departments host thousands of patients every day. AORN A. Cardarelli plays a leading role in emergency 
healthcare, as it is a second-level Emergency-Acceptance Department, providing first aid services and emergency cares in many specialties. Furthermore, the Greater Burns Center, the Anti-Poison Center and the Center for Hepatic Transplants, (Regional Emergency Centers) are present. The Emergency Room (ER) of AORN Cardarelli is a part of a level II ED that manages 94,000 patients per year.

To study the constant overcrowding issue of the ED and the excessive patient waiting times, which greatly increase patient mortality and make inefficient use of resources at the expense of the employee and patient satisfaction, the Lean approach was applied. In particular, for this study, the historical times of accesses to the ER at AORN Cardarelli of Naples from January 2015 to June 2015 were collected, for a total of 16,563 records. Subsequently, the records were analysed and, starting from November 2015, some corrective actions (described in the following) were implemented. Finally, data post-Lean were collected in the period from April 2016 to June 2016.

The first phase of the study was a qualitative analysis, performed by means of several meetings with doctors and interviews with health care staff employed in the ER. In particular, five meetings took place; they involved the managing director, two nurses, a head nurse and a physician for each specialty.

In those meetings, the information, necessary to better understand the process was collected and subsequently analysed by quantitative indicators.

The result of this stage was knowledge of the entire process of admission and treatment of the patients in ER, briefly described in the following.
Upon the arrival of the patient at the ER, the patient is identified, and a triage colour code (red, green, yellow or white) is assigned to him/her after he or she reports his or her symptoms. Then, all patients undergo a reassessment. This revaluation takes place in another room assigned to the second triage after examining the vital signs. With the assignment of the colour code, the patient is assigned to one of the medical specialties (e.g., surgery, medical, orthopaedic, etc.). After the medical examination, instrumental diagnostic tests are activated and executed in the ED Radiology Department (adjacent to the ER) and/or in the Analysis Laboratory (outside the ED). Radiological results are brought by a nurse to the doctor's desk and also sent by the computer system, whereas the laboratory reports are transmitted only by the informatics system. Then, if any specialist advice is required, it is requested. After tests and counselling have been completed, the patient is reassessed by the ER physician to determine discharge, hospitalization or transfer to a short observation room (in which they can remain 24-48 h).

At the end of the analysis of the ER processes, the preliminary stage of Lean assessment, a value stream mapping (VSM) was drafted. VSM is a key tool for identifying opportunities to reduce waste and more tightly integrate process steps, thus improving processing efficiency [4]. In a VSM, key people, resources, activities and information flows, required to deliver a product or service, are made explicit and depicted graphically.

In our project, thanks to the cooperation of all the involved staff, the sequence of the workflow and the time required for each procedure were taken into consideration; the VSM shown in Fig. 1 was obtained.

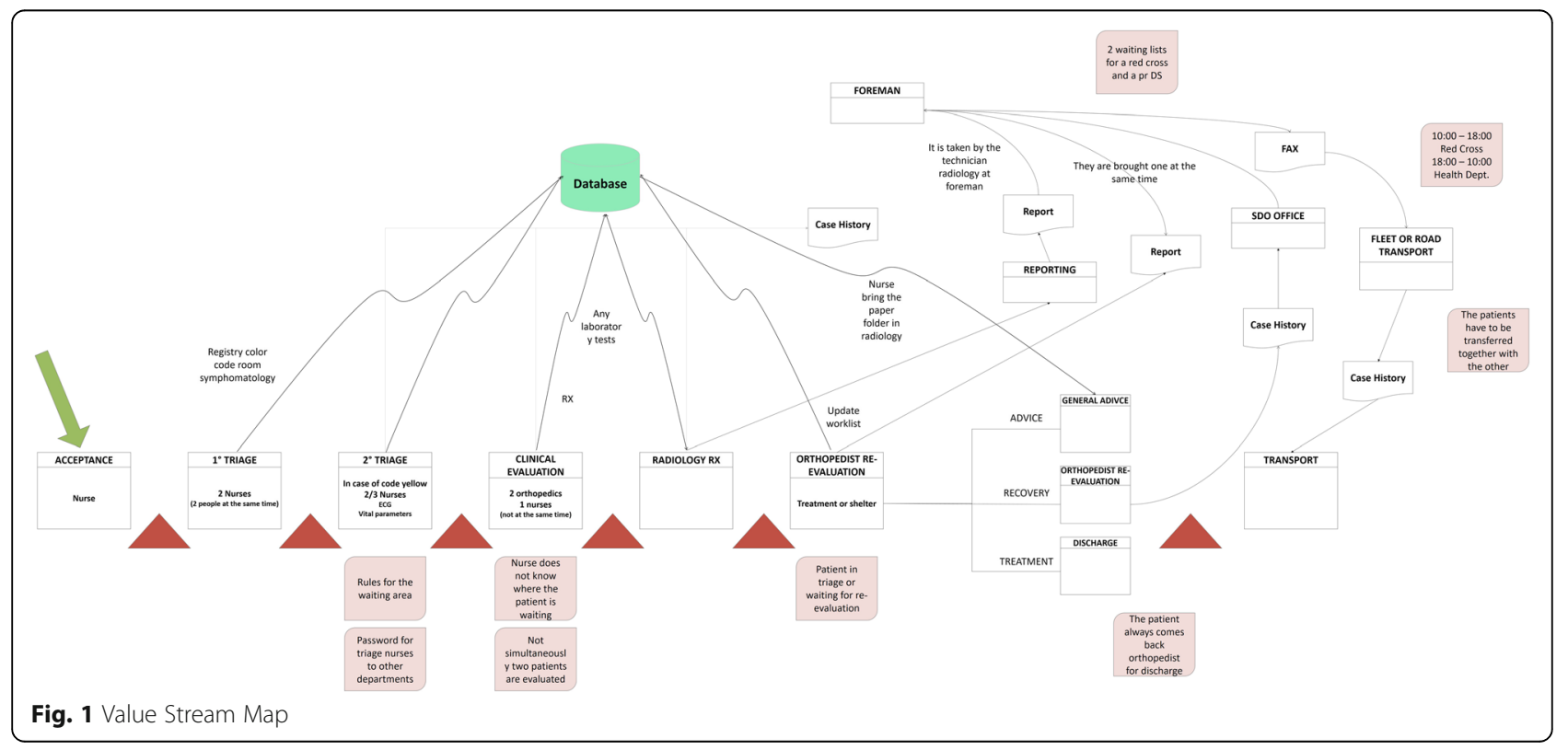


This qualitative analysis was useful to detect the bottlenecks of the workflow and hence to choose the Lean principles on which to base future operations. The criticalities highlighted in this phase were the most time-consuming tasks, such as diagnostic examinations, triage code assignment, and counselling. For the sake of simplicity, the tasks were grouped into macro-categories: Path, Materials, Space, Communication, Logistic and Staff, as shown in Fig. 1.

Subsequently, the study went on with a more quantitative analysis. Literature reports $[15,24,26]$ suggest that ED performance indicators should measure quality of triage, access times, and the quality of the service provided. Therefore, as performance measurements, we chose parameters primarily related to waiting times and service delivery depending on the colour code:

- Percentage of patients with a yellow code examined within 30 min: provides an estimation of the efficiency in managing yellow codes.

- Percentage of patients with green code examined within $1 \mathrm{~h}$ : provides an estimation of the efficiency in managing green codes.

- Percentage of patients with green code not hospitalized with stay times $\leq 4 \mathrm{~h}$.

- Percentage of patients sent to hospitalization with stay times $\leq \mathbf{8} \mathrm{h}$.

- Lead time for colour codes: The time from the patient's arrival at the ER until the patient leaves the ER.

For the quantitative analysis, necessary data were extracted from the health information system commonly used by AORN Cardarelli. The obtained values (presented in the Results section) indicate that $99.8 \%$ of the patients were hospitalized within $8 \mathrm{~h}$. Among green code cases, $94.5 \%$ are hospitalized in the first $4 \mathrm{~h}$ of stay.

At the end of the analysis of the current situation, waste was identified through direct observation of the Lean team on the field. As a result, a balance chart of the "as-is" process was developed. The process determined that the organization of the ER, and hence the workflow to which the patient is subjected, comprises five phases: triage, examination, diagnostic test, advice, and dismissal.

Each phase has added value and is also necessary; moreover, the balance chart technique highlighted the percentage of non-added value for each action. The non-added value was primarily due to delays in information delivery, which must be reduced to optimize the whole process.

What has emerged is that for triage, only 7 min were truly useful; the remaining time represented waiting for the successive phase and is the non-added value of the activity.
The examination took 13 min on average. Approximately, approximately $5 \mathrm{~min}$ were needed for the request of diagnostic tests and anamnesis; both activities are necessary, even if without value for the patient. In the remaining time, the patient waited for the diagnostic test (activity without added value and non-necessary).

The time required for the diagnostic test (radiography, echography, etc.) included approximately $12 \mathrm{~min}$ for the test itself, $10 \mathrm{~min}$ for the clinical report (necessary but non-added value activity) and more than $1 \mathrm{~h}$ elapsed in queues and delays before the report was available in the informatics system of the hospital.

The majority of the advice activity was due to waiting time; only $10 \mathrm{~min}$ were dedicated to the specialist medical examination and 10 to writing the report.

The last activity, dismissal, was the shortest, including approximately $8 \mathrm{~min}$ for the discharge procedure, $3 \mathrm{~min}$ on average for the exit report and approximately $7 \mathrm{~min}$ of waiting.

The activities involved in each phase of the process (patient stay in ER) are summarized in Table 1.

At the end of the analysis (values presented in the Results section), the average time elapsed for the whole process was $4 \mathrm{~h}$ and $18 \mathrm{~min}$, of which $80 \%$ were due to non-value added activities, some of which were necessary but the majority of which were primarily waiting times.

Based on the above-mentioned analysis, conducted in accordance with Lean methodology, as introduced at the beginning of this section, in the second half of 2015, corrective actions were planned and implemented to simplify and speed up the procedures; hence, the process was redesigned to minimize or completely eliminate waste.

For example, a re-engineering process was performed to achieve the following: reduce the waiting time associated with report consultation; better organize the nurse stations with particular attention to drug layout to facilitate daily operations; and organize medical shifts to optimize time and resources.

As a result of the analysis of the "as-is" process, the corrective actions were primarily devoted to:

a) standardize the work and reduce ambiguity;

b) connect people who are interdependent;

c) create seamless uninterrupted workflow through the process;

d) allow staff to investigate process problems and to develop, test and implement countermeasures with a "scientific method" [9].

In particular, the key interventions reported in Table 2 were put in place. The main improvement actions concern the computerization of all the main procedures and 
Table 1 Added- and non-added-value activities

\begin{tabular}{|c|c|c|c|c|}
\hline Phase & Activity & $\begin{array}{l}\text { Added } \\
\text { value (min) }\end{array}$ & $\begin{array}{l}\text { Non added } \\
\text { value (min) }\end{array}$ & $\begin{array}{l}\text { Non added value } \\
\text { but necessary (min) }\end{array}$ \\
\hline \multirow[t]{2}{*}{ Triage } & Triage & 7 & & \\
\hline & Waiting for examination & & 32 & \\
\hline \multirow[t]{3}{*}{ Examination } & Examination & 13 & & \\
\hline & Request for diagnostic tests & & & 44 \\
\hline & Waiting for diagnostic tests & & 5 & \\
\hline \multirow[t]{3}{*}{ Diagnostic Test } & Diagnostic tests & 12 & & \\
\hline & Clinical report & & & 60 \\
\hline & $\begin{array}{l}\text { Clinical report available in the } \\
\text { IT system }\end{array}$ & & 10 & \\
\hline \multirow[t]{3}{*}{ Advice } & Waiting for specialist advice & & 10 & \\
\hline & Specialist medical examination & 10 & & \\
\hline & Report writing & & & 20 \\
\hline \multirow[t]{3}{*}{ Dimissal } & Waiting for the dismissal & & 3 & \\
\hline & Discharge procedure & 8 & & \\
\hline & Exit reporting & & & 6 \\
\hline
\end{tabular}

the reorganization of the medical staff with well-defined roles and goals.

With respect to the "computerization" intervention in Table 2, it is worth mentioning that the informatics system present at the AORN Cardarelli hospital before the Lean interventions consisted of the use of a first aid management system perfectly interfaced with the diagnostic services applications, including radiology, clinical analysis laboratory, and transfusion. Upon patient admission, the 1st triage code assignment is performed, and the personal data sheet is filled out on the ED management system. Depending on the assigned code, the patient is placed into different assistance and treatment paths. During the medical examination, the doctor writes the diagnosis and prescribes any diagnostic test, advice and possible therapy. Diagnostic examinations and consultations are requested through an informatics system called "Order Entry," which maintains a communication between the ED management system and other applications. Once the examinations have been reported, they are automatically re-sent through the "Order Entry" to the ED management system, which stores the data until the doctor visualizes

Table 2 Key Interventions

\begin{tabular}{|c|c|c|}
\hline Type & Description & Time \\
\hline 5S Tecnique & Re-organization of the Nurses station & February 2016 \\
\hline \multirow[t]{5}{*}{ Visual } & Identification of the staff & November 2015 \\
\hline & $\begin{array}{l}\text { Vertical and horizontal information plaques } \\
\text { for shared spaces }\end{array}$ & December 2015 \\
\hline & Define the card for the patient waiting for first examination & March 2016 \\
\hline & Definition of the care path manager panel & March 2016 \\
\hline & Team leader becomes care path manager - goal setting & January 2016 \\
\hline Triage & Project presentation meeting & December 2015 \\
\hline \multirow[t]{4}{*}{ Flow } & Definition of the medical tutor role & December 2015 \\
\hline & Strategic management of medical shifts & January 2016 \\
\hline & $\begin{array}{l}\text { Definition of a minimum number of medical examinations } \\
\text { per shift for each location + periodic calculation }\end{array}$ & January 2016 \\
\hline & Sharing with staff and periodic reports & January 2016 \\
\hline Support & $\begin{array}{l}\text { Define who needs the stretcher at the entrance, and } \\
\text { limiting its use and replacing it when possible with a } \\
\text { wheelchair }\end{array}$ & December 2015 \\
\hline Computerization & $\begin{array}{l}\text { Create a web application that notifies the arrival of reports } \\
\text { in real time }\end{array}$ & December 2015 \\
\hline
\end{tabular}


them. Possible advice is automatically sent in the same way. The therapy administered is recorded in the appropriate electronic record related to the patient, and the system proceeds with discharge or transfer of the patient by saving in the appropriate electronic record all of the necessary data and information for the discharge report.

The Takt Time [37] was then calculated for all of the activities to estimate the degree of satisfaction with the input demand. The Takt Time is an estimate of the desirable duration (from the patient's point of view) of each activity of the healthcare process. The duration should be sufficient to satisfy the patient's demand without creating queues or dead times (non-added-value activities). In essence, the Takt Time proves to be an interesting indicator of the patient's satisfaction as well as of the efficiency of the process and makes it possible to define the rhythm through which the activities must be performed to meet the services' demand.

Finally, the analysis was repeated after the collection of data concerning the period here called "post-Lean," and the obtained results were compared. In particular, a statistical analysis by means of a $t$-test was performed on the identified performance indicators of the process.

\section{Results}

In this section, the results obtained after the Lean methodology employment are presented.

Table 3 displays performance measurements before and after the Lean interventions.

In Fig. 2, a balance chart of the process before and after the Lean interventions is reported.

Based on Fig. 2, it is possible to observe that a reduction of the overall times (total of the five phases, triage, examination, diagnostic test, advice, and dismissal) was achieved through the implementation of the corrective actions after the Lean interventions. In particular, interventions devoted to improving the information system and the staff formation and collaboration lead to a reduction in delays in information delivery, identified as non-added-value activities.

At this point, it is worth remembering that the analysis of the "as-is" process highlighted that most of non-added value actions are waiting times, so we detailed these times for each colour code:

- Waiting time triage I - triage II,

- Waiting time triage I - taken into care,

- Waiting time taken into care - dismissal,

- Waiting time triage I - dismissal.

Figure 3 depicts the stay time control chart of patients in the ER divided by colour code.

Finally, a comparison of the process before and after the application of the Lean methodology and the results of the $t$-test are reported in Table 4. The results confirm that the key interventions have significantly improved patient's throughput times.

\section{Discussion}

Over time, the Lean approach, referring to the model adopted by Toyota exclusively for production, has expanded to involve the management and administrative processes of different companies: a true Lean Thinking encoded in Lean Management techniques. Today, Lean is not merely a set of tools but is based on individual involvement to create a culture of no ambiguity and quickly resolving problems. Lean consists of a management strategy applicable to all organizations because it involves the improvement of the processes. Lean is embodied in the identification of processes, in mapping the activities and in the continuous search and elimination of waste to produce more value with less consumption. In particular, to implement Lean thinking in a healthcare organisation, a theoretical path has to be followed whose main steps are as follows: training of staff and raising awareness about wastes involved in the processes;

Table 3 Performance Measurements (before and after Lean interventions)

\begin{tabular}{lll}
\hline & Before lean & After lean \\
\hline Performance Measurements & Percentage (\%) & Percentage (\%) \\
Patients with a yellow code examined within 30 min & 53,6 & 56,9 \\
Patients with a green code examined within 1 h & 52,6 & 54,3 \\
$\begin{array}{l}\text { Patients with a green code sent to hospitalization } \\
\text { with a stay time } \leq 4 \mathrm{~h}\end{array}$ & 94,8 & 96,8 \\
Patients sent to hospitalization with a stay time $\leq 8 \mathrm{~h}$ & 99,8 & 99,8 \\
Performance Measurements & Average \pm std. (min) & Average \pm std. (min) \\
Lead Time for red code & $72 \pm 36$ & $71 \pm 30$ \\
Lead Time for yellow code & $151 \pm 100$ & $147 \pm 67$ \\
Lead Time for green code & $164 \pm 116$ & $163 \pm 120$ \\
Lead Time for white code & $160 \pm 173$ & $158 \pm 156$ \\
\hline
\end{tabular}



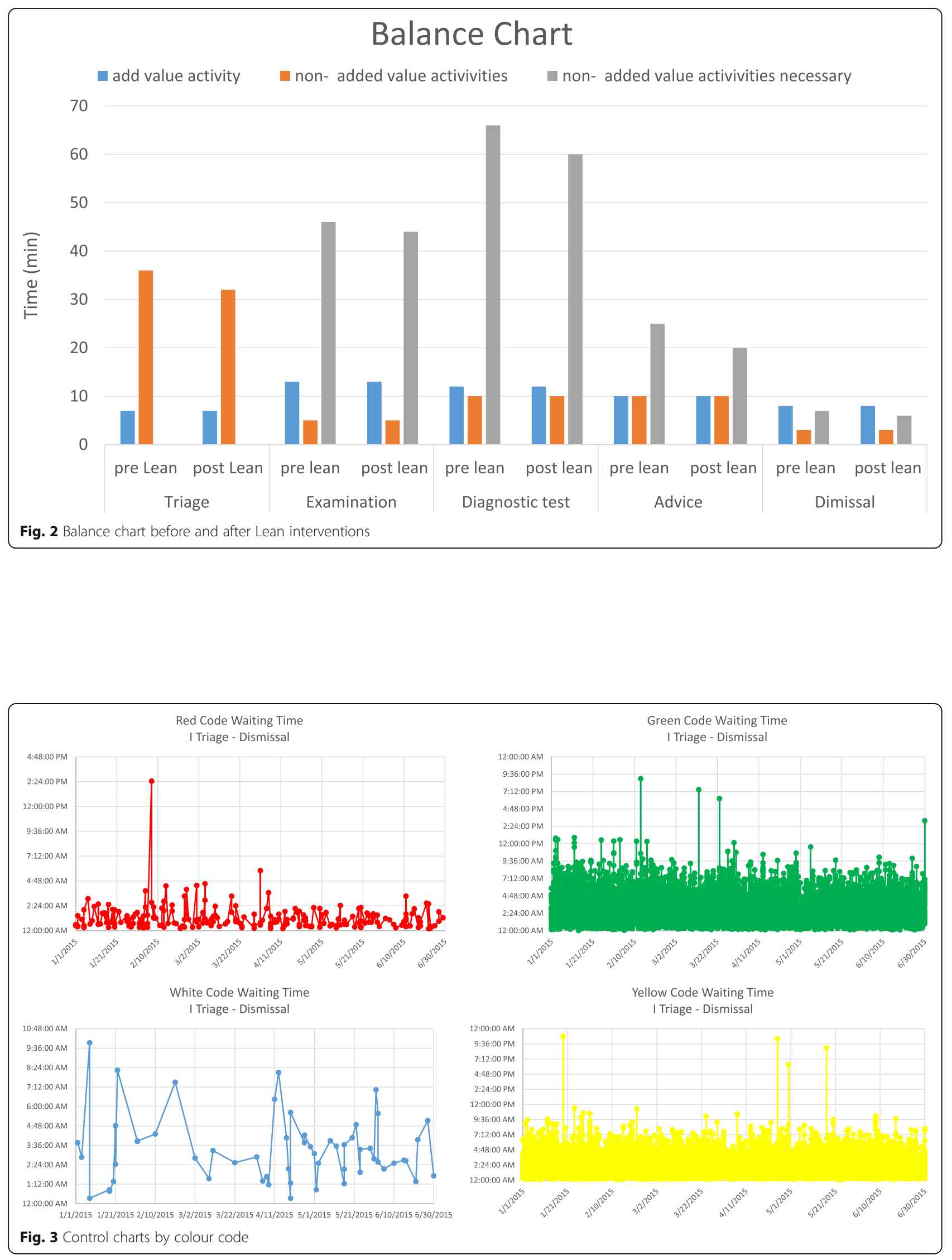
Table 4 Patient throughput times (before and after Lean interventions)

\begin{tabular}{llll}
\hline Variable & $\begin{array}{l}\text { Average }- \text { STD } \\
\text { pre-Lean }(N=16.563)\end{array}$ & $\begin{array}{l}\text { Average }- \text { STD } \\
\text { post-Lean }(N=17.147)\end{array}$ \\
\hline $\begin{array}{l}\text { Waiting time } \\
\text { I triage - II triage }\end{array}$ & $00: 22: 54-00: 28: 25$ & $00: 21: 24-00: 26: 55$ \\
$\begin{array}{l}\text { Waiting time } \\
\text { I triage - taken into care }\end{array}$ & $01: 47: 55-01: 14: 44$ & $01: 41: 55-01: 14: 44$ \\
$\begin{array}{l}\text { Waiting time } \\
\text { taken into care - dismissal }\end{array}$ & $02: 31: 02-01: 27: 18$ & $02: 19: 12-01: 03: 20$ \\
$\begin{array}{l}\text { Waiting time } \\
\text { I triage - dismissal }\end{array}$ & $04: 18: 57-01: 52: 11$ & 0.001 \\
\hline
\end{tabular}

determining the precise sequence of activities, eliminating those without add value; improving the processes through agile and quick responses to remove waste as soon it is identified [11].

Many authors have analysed and proposed Lean applications in health care through case studies [11, 25-28]. In this work, we proposed a new, interesting case study based on the implementation of the Lean methodology to reduce waiting times in the ER and improve the flow of patients between the emergency room and recovery areas. We followed the theoretical path described mentioned, and, among principles and tools of the Lean methodology, we chose those considered the most important in healthcare management, such as VSM and 5S.

The aim was to govern the flows that the ED dictates to the entire operation of the Cardarelli hospital and to try to prevent useless waits in conditions that are often not compliant with care and assistance needs.

On the basis of the principles of Lean thinking, the medical directorate of the Cardarelli Hospital in Naples decided to review the patient's path from the arrival in the ER to admission, recovery and discharge. This path is transversal to several operating units and includes processes pertinent to hospitals and others of territorial relevance. In detail, a re-engineering process that improves the management of medical reports and the creation of a web application that provides notifications on the arrival of reports in real time have been employed and/or developed to reduce the waiting time related to the doctors' consultation. A series of operations, such as the definition of the role of the physicians and of a minimum number of visits per shift, as well as the installation of information plaques for shared spaces, has considerably reduced patient's time from phase to phase. The non-wasted time is dedicated to the patient and provides the same service but at a higher level of quality and security. Moreover, delivering the same service in a shorter time ensures less waiting time not only for the patient involved but also for those others waiting.

The described theoretical path can be followed independently of the specific environment, which only influences the concrete and practice actions that must be implemented.

\section{Conclusions}

In conclusion, the work demonstrated that by strictly following the theoretical path, choosing suitable tools, and applying the principles and methods of Lean Thinking to the healthcare processes, it is possible to increase the efficiency of services, reduce waste in terms of waiting times, and improve the quality of the working environment for operators.

\section{Abbreviations}

ED: Emergency department; ER: Emergency room; NHS: National health service; TPS: Toyota production system; VSM: Value stream map

\section{Acknowledgements}

The authors gratefully acknowledge Fiorella Paladino, Primary of the Emergency Department, AORN Cardarelli Hospital, Naples, Italy; Enrico Pasquale Acerra, Healthcare software specialist and Consultant at AORN Cardarelli; and Dott. Pasquale Indizio, director of informatic service, AORN Cardarelli Hospital.

\section{Funding}

Not applicable.

\section{Availability of data and materials}

The datasets used and analysed during the current study are available from the corresponding author on reasonable request.

\section{Authors' contributions}

IG, DCMV and FA performed the data analyses and drafted the manuscript. RM helped in the design of the study and revised the work critically for important intellectual content. RM, BA and DCMV contributed to the collection and interpretation of data. VC, TM and CM participated in the conception and the design of the study and gave final approval of the version to be published. All authors have been involved in drafting and critically revising the manuscript. All authors approved the final manuscript and guarantee its accuracy and integrity.

\section{Ethics approval and consent to participate}

The authors declare that, given the nature of the collected and analysed data, no ethic authorizations and no consent declarations were required. The Italian National Health Service (Law N.211 24/06/2003) requires the preliminary ethical approval of research only in cases of clinical trials of investigational medicinal products, medical devices, drug/device combination, and clinical investigation. Our study is solely a service/satisfaction evaluation. Furthermore, Italian law on privacy and data protection (Law N. 196/2003) requires formal actions only in cases of personal and/or sensitive data. Our analysis is completely anonymous, and no personal information was linked or linkable to a specific respondent. Moreover, given the nature of the study, no sensitive data were collected or analysed.

Consent for publication Not applicable. 


\section{Competing interests}

The authors declare that they have no competing interests.

\section{Publisher's Note}

Springer Nature remains neutral with regard to jurisdictional claims in published maps and institutional affiliations.

\section{Author details}

'Department of Public Health, School of Medicine and Surgery, University of Naples 'Federico II', Naples, Italy. ${ }^{2}$ Department of Medical and Surgical Sciences, University 'Magna Graecia' of Catanzaro, Catanzaro, Italy. ${ }^{3}$ Responsible for the Programming and Health Planning Unit, Hospital "Antonio Cardarelli", Naples, Italy. ${ }^{4}$ Hospital "Antonio Cardarelli", Naples, Italy. ${ }^{5}$ Department of Electrical Engineering and Information Technology (DIETI), University of Naples 'Federico II', Naples, Italy. ${ }^{6}$ Scientific Clinical Institutes Maugeri IRCCS, Telese, Italy.

Received: 8 May 2018 Accepted: 26 October 2018

Published online: 03 December 2018

\section{References}

1. Brandao de Souza L. Trends and approaches in lean healthcare. Leadersh Health Serv. 2009;22.2:121-39.

2. Ohno T. Toyota production system: beyond large-scale production. crc Press; 1988.

3. Niu G, Lau D, Pecht M. Computer manufacturing management integrating lean six sigma and prognostic health management. IJPE. 2010;6(5):453-66.

4. Stoiljkovi V, Trajkovi J, Stoiljkovi B. Lean six sigma sample analysis process in a microbiology laboratory. J Med Biochem. 2011;30:346-53.

5. Black J, Miller D. The Toyota way to healthcare excellence: increase efficiency and improve quality with lean, ACHE; 2008.

6. Mazzocato $P$, et al. Lean thinking in healthcare: a realistic review of the literature. Qual Saf Health Care. 2010.

7. Womack JP, Jones DT. Lean thinking — banish waste and create wealth in your corporation. J Operational Res Soc. 1996:48.11:1148.

8. Staats BR, Brunner DJ, Upton DM. Lean principles, learning, and knowledge work: evidence from a software services provider. JOM. 2011;29.5:376-90.

9. Bowen HK, Spear S. Decoding the DNA of the Toyota production system. Harvard Business Review. 1999;99.

10. George ML. Lean six sigma for service, New York. NY: MC GR a W-HILL, MHE; 2003

11. Chiarini A. Lean thinking implementation in the public healthcare: results from Italy, in 17th Toulon-Verona international conference "excellence in services", Toulon-Verona International Conference; 2014.

12. Al-Araidah O, Momani A, Khasawneh M, Momani M. Lead-time reduction utilizing lean tools applied to healthcare: the inpatient pharmacy at a local hospital. J Healthc Qual. 2010;32(1):59-66.

13. Wiboonrat M. Applying lean six sigma for public healthcare services. JIST 2011;2(1):1-11.

14. Fillingham D. Lean healthcare: improving the Patient's experience, healthcare improvements; 2008.

15. Wineke A.M. van Lent N Goedbloed W.H. van Harten. Improving the efficiency of a chemotherapy day unit: Applying a business approach to oncology, 2009 Eur J Cancer. 1990;45.5:800-06.

16. Bisgaard S, Does RJMM. Quality Quandaries: healthcare quality: reducing the length of stay at a hospital. Qual Eng. 2008;21.1:117-31.

17. Dickson EW, Singh S, Cheung DS, Wyatt CC, Nugent AS. Application of lean manufacturing techniques in the emergency department. J Emerg Med. 2009:37(2):177-82.

18. Arbós LC. Design of a rapid response and high efficiency service by lean production principles: methodology and evaluation of variability of performance. Int J Prod Econ. 2002;80.2:169-83.

19. Connelly LG, Aaron EB. Discrete event simulation of emergency department activity: a platform for system-level operations research. Acad Emerg Med. 2004;11.11:1177-85.

20. Raab SS, Andrew-Jaja C, Condel JL, Dabbs DJ. Improving Papanicolaou test quality and reducing medical errors by using Toyota production system methods. Am J Obstet Gynecol. 2006;194(1):57-64

21. Niemeijer GC, Trip A, Ahaus KT, Does RJ, Wendt KW. Quality in trauma care: improving the discharge procedure of patients by means of lean six sigma. J Trauma Acute Care Surg. 2010;69(3):614-19.
22. Vissers J, Beech R. Health operations management: patient flow logistics in health care London; 2005.

23. Melillo P, Delle Donne A, Improta G, et al. Assessment of patient satisfaction using AHP model: an application to a service of pharmaceutical distribution. In: In Proceedings of the International Symposium on the Analytic Hierarchy Process; 2011

24. Improta G, Fratini A, Triassi M. Health technology assessment:an essential approach to guide clinical governance choice on risk managment. In: Risk Managment for the Future-Theory and Cases; 2012.

25. Improta G, Balato G, Romano M, et al. Lean six sigma: a new approach to the management of patients undergoing prosthetic hip replacement surgery. J Eval Clin Pract. 2015;21(4):662-72.

26. Converso G, Improta G, Mignano M. A Simulation Approach for Agile Production Logic Implementation in a Hospital Emergency Unit. In: Intelligent Software Methodologies, Tools and Techniques, 532, 623-634 Springer International Publishing - Proceedings of the 14th International Conference (SoMet 2015), Naples, Italy September 15-17; 2015.

27. Montella $\mathrm{E}$, et al. The application of lean six sigma methodology to reduce the risk of healthcare-associated infections in surgery departments. J Eval Clin Pract. 2017:23(3):530-9.

28. Improta G, Balato G, Romano M, Ponsiglione AM, Raiola E, Russo MA, Cesarelli $\mathrm{M}$, et al. Improving performances of the knee replacement surgery process by applying DMAIC principles. J Eval Clin Pract. 2017;23(6):1401-07.

29. Improta G, Russo MA, Triassi M, Converso G, Murino T, Santillo LC. Use of the AHP methodology in system dynamics: modelling and simulation for health technology assessments to determine the correct prosthesis choice for hernia diseases. Math Biosci. 2018;299:19-27.

30. Improta $\mathrm{G}$, et al. Reducing the risk of healthcare-associated infections through lean six sigma: the case of the medicine areas at the Federico II University Hospital in Naples (Italy). J Eval Clin Pract. 2018;24(2):338-46.

31. Holden RJ. Lean thinking in emergency departments: a critical review. Ann Emerg Med. 2011;57.3:265-78.

32. Ben-Tovim DI, Bassham JE, Bennett DM, Dougherty ML, Martin MA, O'Neill SJ, Szwarcbord MG. Redesigning care at the Flinders medical Centre: clinical process redesign using "lean thinking". Med J Aust. 2008;188(6):S27.

33. Dickson EW, Anguelov Z, Vetterick D, Eller A, Singh S. Use of lean in the emergency department: a case series of 4 hospitals. Ann Emerg Med. 2009; 54(4):504-10.

34. Hoot NR, Aronsky D. Systematic review of emergency department crowding: causes, effects, and solutions. Ann Emerg Med. 2008;52.2:126-36.

35. Derlet RW, Richards JR. Overcrowding in the nation's emergency departments: complex causes and disturbing effects. Ann Emerg Med. 2000; 35.1:63-68.

36. Glouberman S, Mintzberg $\mathrm{H}$. Managing the care of health and the cure of disease_Part I: differentiation. HCMR. 2001;26(1):56-69.

37. Seth D, Gupta V. Application of value stream mapping for lean operations and cycle time reduction: an Indian case study. Prod Plan Control. 2005; 16(1):44-59.

Ready to submit your research? Choose BMC and benefit from:

- fast, convenient online submission

- thorough peer review by experienced researchers in your field

- rapid publication on acceptance

- support for research data, including large and complex data types

- gold Open Access which fosters wider collaboration and increased citations

- maximum visibility for your research: over $100 \mathrm{M}$ website views per year

At BMC, research is always in progress.

Learn more biomedcentral.com/submission 